\title{
INTRATUNNEL THE EFFECT OF ADMINISTRATION OF BONE MARROW MESENCHYMAL STEM CELLS (BM-MSCS) AND VASCULAR ENDOTHELIAL GROWTH FACTOR (VEGF) TENDON-BONE TO INTERFACE HISTOLOGICAL GRAFT ANTERIOR CRUCIATE LIGAMENT APPEARANCE AFTER RECONSTRUCTION IN RABBITS
}

\author{
Atria Abirama $^{1}$, Dwikora Novembri Utomo ${ }^{1,2}$, Mouli Edward ${ }^{1,2}$ \\ ${ }^{1}$ Department of Orthopaedic, Faculty of Medicine, Airlangga University -Dr. Soetomo Hospital, \\ Surabaya, Indonesia. \\ ${ }^{2}$ Stem Cell Research and Development Center, Universitas Airlangga Surabaya, East Java, Indonesia.
}

\begin{abstract}
The success of the Anterior Cruciate Ligament (ACL) reconstruction using a tendon graft is determined by integration in the bone tendon-graft interface on the bone tunnel. The use of stem cells and growth factors proved to accelerate the healing of the bone tendon-graft interface. The aim of this study was to inveestigate the difference of histology picture in the tendon-bone tunnel model after ACL reconstruction with intratunnel intravenous allogenic bone marrow mesenchymalstemcells (BMMSCs) and intratunnel vascular endothelial growth factor (VEGF). This research used Post-Test Only Control Group design with 20 rabbits divided into treatment group and control group. Each group performed histologic image evaluation (thickness of collagen fiber or sharpey fiber) at week 3 and 6. Evaluation of histology overview at week 3 and week 6 showed a significantly thicker thickness of collagen fiber or sharpey fiber in treatment group compared with control group ( $\mathrm{p}<0.05)$. Intravenous administration of BM-SCs and VEGF after ACL reconstruction can speed healing of the bone tunnel significantly from week 3 and 6 . The study by Faridyan et al has concluded that intravenous BM-SCs + VEGF increased ultimate tension strength in the bone-tendon interface significantly. In this study, intravenous administration of BM-SCs and VEGF gave histologic images showing acceleration of bone tunnel healing.
\end{abstract}

Keywords:Anterior cruciate ligament reconstruction, allogenic bone marrow mesenchymal stem cells, vascular endothelial growth factor, graft tunnel healing, and Sharpey fiber.

\section{INTRODUCTION}

The increase in sports activities will directly increase the incidence of sports injuries. Most sports injuries occur in the knee, and ACL injuries occur in $30-40 \%$ of a knee injury. (Baxter et al. 2010). ACL injuries will cause a variety of knee functional impairment due to the anteriorinstability and rotatoryinstability.ACL injuries can also cause injury to the meniscus and cause early osteoarthritis. On ACL injuries, can be given conservative or operative therapy (Alpert et al. 2008). The goal of surgery on ACL reconstruction is to obtain a mechanically stable knee, thereby decreasing the risk of injury to the meniscus and joint surfaces by decreasing anteroposterior joint movement (Myklebust\& Bahr 2005) . 
The main disadvantage of ACL reconstruction using tendon graft is the weak initial linkage in the bone-tendon graft interface. The healing phase between bonetendon graft in the bone tunnel begins with the formation of fibrovascular tissue between the tendon and bone in the bone-tendon graft interface. This layer will eventually compose fibers perpendicular to each other so as to resemble Sharpey's fibers. The existence and amount of sharpey's fiber is what affects the strength of the fixation between bone-tendon graft (Weiler et al., 2002).

Several studies have shown that the use of Bone Marrow-Derived Mesenchymal Stem Cells (BMSCs) in bone tunnel improves the healing of bone-tendon graft in rabbit-bred animals. This is achieved by the formation of perpendicular collagen fibers that connect the tendon to the bone (sharpey's fibers) and the increased proliferation of cartilage-like cells by week four (Dong et al. 2012; Ma et al. 2007; Ouyang 2004).

The use of growth factor is also proven to accelerate the healing of graft-bone tunnel. BMPs and GFs play a role in the activation and acceleration of bone in growth, collagen fiber synthesis, and fibro cartilaginous differentiation in bone tendon-graft interfaces with the primary goal of achieving bone tendon-graft insertion similar to normal ACL

\section{METHODS}

This research was a true experimental laboratory study using post-test only control group design. The research unit used New
(Milano et al., 2007). Giving Vascular Endothelial Growth Factor (VEGF) increases neovascularization, stimulates fibroblast cell proliferation, collagen synthesis and cell growth in bone tunnels (Deehan\&Cawston 2005). The provision of fibrin plugs on the articular side to block the entry of synovial fluid into the bone tunnel and is expected to have a positive effect on the intravenous bone marrow-derived mesenchymal stem cell (BMSCs) + Vascular Endothelial Growth Factor (VEGF) against bone tendon-graft healing. Giving Vascular Endothelial Growth Factor (VEGF) increases neovascularization, stimulates fibroblast cell proliferation, collagen synthesis and cell growth in bone tunnels (Deehan\&Cawston 2005). The provision of fibrin plugs on the articular side to block the entry of synovial fluid into the bone tunnel and is expected to have a positive effect on the intravenous bone marrow-derived mesenchymal stem cell (BMSCs) + Vascular Endothelial Growth Factor (VEGF) against bone tendon-graft healing.

Based on the above thought, this research was made to know the difference of histology picture on bone-tendon graft interface after reconstruction of Anterior Cruciate Ligament (ACL) with intratunnel Vascular Endoteric Stem Cells (BMSCs) + Vascular Endothelial Growth Factor (VEGF).

Zealand White Rabbit, male, weighing 30004000 gram animals divided into four groups randomly. The number of experimental units for this study is 5 for each his group. 
Research was carried out exponentially in the laboratory. The study was divided into 4 groups consisting of 2 (two) treatment groups (P1 and $\mathrm{P} 2)$, ie the injection of BMSCs + VEGF intratunnel after ACL reconstruction surgery with tendon graft. Evaluation was done

\section{RESULTS}

Evaluation of thickness measurement of at week 3 for P1 group and week 6 for group P2. In 2 (two) control groups (K1 and K2), ie groups without BMSCs + VEGF intratunnel after ACL reconstruction surgery with tendon graft. The evaluation was done at week 3 for K1 group and week 6 for K2 group. collagen fiber showed the thickness on treatment group and control group in week

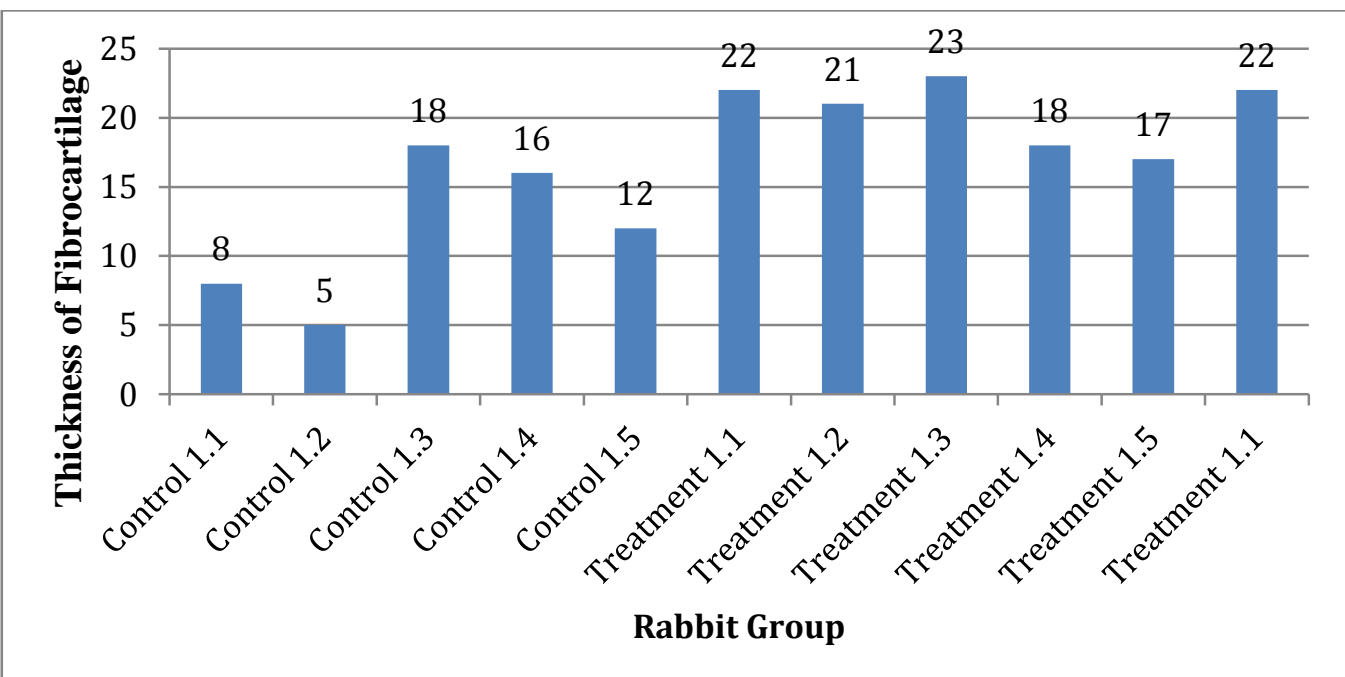

Graphic 1. The graphic of thickness evaluation of collagen fiber or sharpey fiber on week 3. It showed the thickness of collagen fiber or sharpey fiber on control group in week 6 and the thickness of collagen fiber or sharpey fiber on treatment group in week 6 .
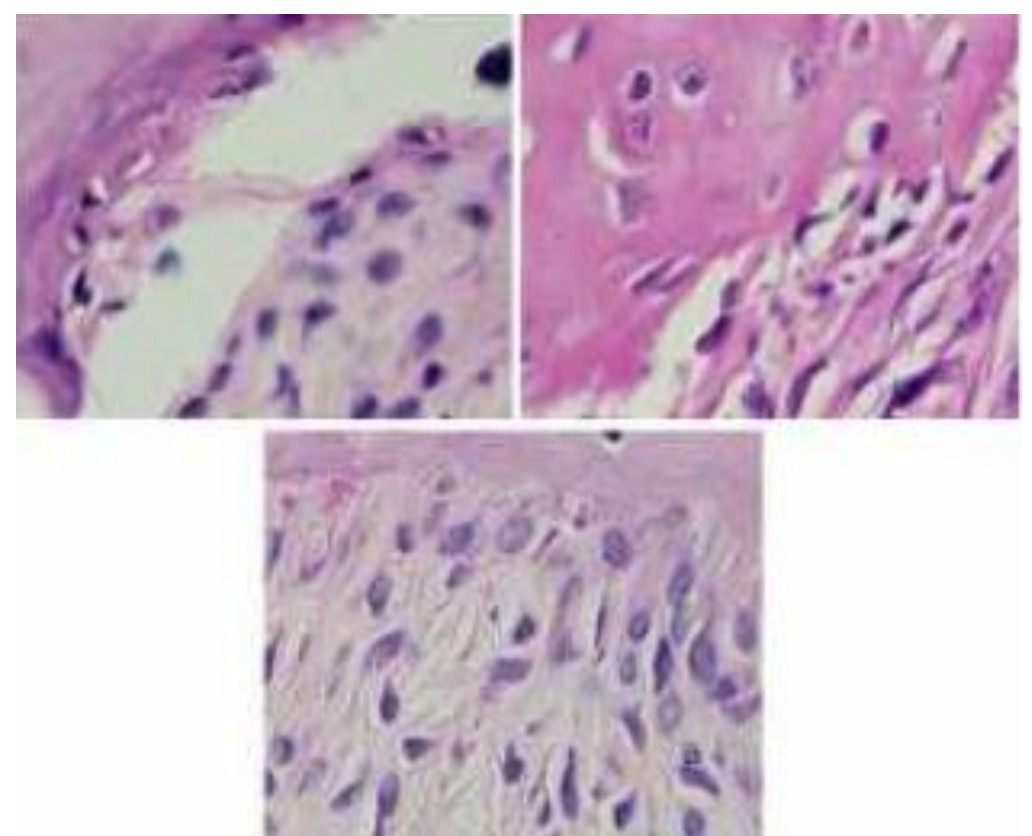

Figure 2. Histology of collagen fiber or Sharpey fiber, 1. Control the third week; 2. Treatment of the 
third week; 3. Treatment sixth week.

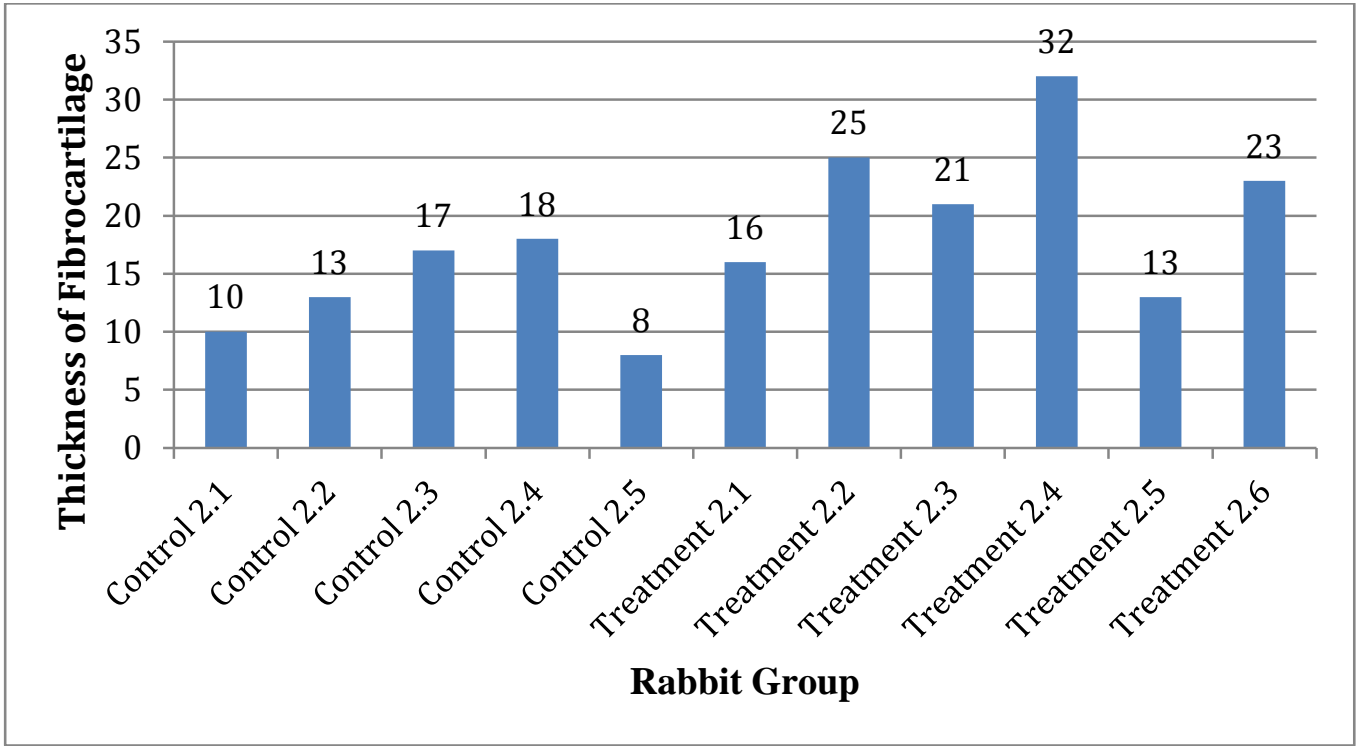

Figure 3. Graph of evaluation of the thickness of collagen fiber or sharpey fiber in the sixth week.

The data showed that in the third week, the treatment group using BM-MSCs and VEGF intratunnel had significantly higher collagen fiber or sharpey fiber thickness than control group $(\mathrm{p}<0.05)$

Table 1. Comparison of the thickness of collagen fiber or sharpey fiber control and treatment groups in the third week.

\begin{tabular}{c|c|c|c}
\hline Group & $\mathbf{N}$ & Mean \pm SD & p \\
\hline Control & 5 & $11.80 \pm 5.40$, & 0 \\
Treatment & 6 & $20.50 \pm 2.43$ & \\
\hline
\end{tabular}

After 6 weeks, the study show that there is significant difference between control and treatment group. The treatment group given

\section{DISCUSSION}

This study used a hamstring tendon graft because, it is one of an alternative choice of graft in ACL reconstruction. The success of ACL reconstruction depends on the healing process on the bone-tendon graft on the bone tunnel. This layer will eventually arrange the
BM-SCs and VEGF intratunnel,has largercollagen fiber or Sharpey fiber than the control group.

Table 2. Comparison of the thickness of the collagen fiber or fiber Sharpey on control groups and treatment groups in 6 weeks treatment .

\begin{tabular}{c|c|c|c}
\hline Group & $\mathbf{N}$ & Mean \pm SD & p \\
\hline Control & 5 & $13.20 \pm 4.32$ & 0 \\
Treatment & 6 & $21.67 \pm 6.74$ & \\
\hline
\end{tabular}

Compared to evaluate the thickness of the collagen fiber or Sharpey fiber treatment group at week 3 and week 6 , Table 3 does not found significant differences between the two groups $(\mathrm{p}>0.05)$

fibers that are perpendicular to each other to resemble Sharpey's fiber. The existence of sharpey's fiber determines the pullout strength of ACL reconstruction. This study was a true experimental study that aimed to determine the difference in the thickness of collagen fiber or sharpey's fiber in bone-tendon graft interfaces 
after ACL reconstruction with intravenous injection of BM-SCs and VEGF. The evaluation was performed in the third and sixth weeks after reconstruction assumed that there will be a process of increasing osteoblast cells, cholesterol and fibroblasts and blood vessels in the third week. While in the sixth week, the cells will multiply and mature. Thus, the relationship between bone-tendon graft will be stronger. It is indicated by the formation of sharpey's fiber seen along the tendon associated with bone (Rodeo et al., 1993; Liu et al. , 1997)

Bone Marrow-derived Mesenchymal Stem Cells (BM-SCs) are multipotent stem cells that can be used as cell sources for tissue repair and cell therapy engineering (Griffin et al., 2010). The provision of growth factor VEGF has been shown to increase vascularization and improve the quality of fibroblast tissue integration between bone-tendon graft (Zhang et al., 2003). In this study, the result of comparative analysis using independent t-test showed significant increase of collagen fiber or sharpey's fiber thickness in ACL reconstruction treatment group with injection of BM-SCs and VEGF intratunnel compared with control group both in third week observation on femur tunnel and tibia $(\mathrm{p}<0.05)$ and at the sixth week observation in the femoral tunnel as well as the tibia ( $\mathrm{p}<0.05$ ). There was no significant difference in term of the thickness of collagen fiber or sharpey's fiber between the sixth week treatment group and third week treatment group.

A study conducted by Ouyang et al found that in the control group without the

administration of BM-SCs demonstrated the fixation between bone-tendon graft, which was indicated by reorganization of fibrous tissue on the longitudinal axis of the bone tunnel, only in the sixth week obtained a little picture of collagen fiber that resembled sharpey's fiber. In contrast, the group with intratunnel BM-SCs exhibited more perpendicular collagen fiber or sharpey's fiber. In addition, in the treatment group demonstrated proliferation of cartilage-like cells and the formation of fibrocartilage-like tissue. So this study concluded that the administration of BM-SCs in bone tunnel can accelerate the healing of bone-tendon graft in bone tunnel (Ouyang 2004).

Research on the use of growth factor to accelerate the healing of bone tunnel has been done. Research conducted by Ma et al using various doses of rhBMP-2 in ACL reconstruction mode in rabbits has concluded that the formation of new bone and integration to tendon graft was influenced by the dose of rhBMP-2 (Ma et al., 2007). While research conducted by Martinek et al has concluded that BMP-2 significantly increased the integration of semitendinosus tendon graft in bone tunnel after ACL reconstruction of rabbits (Martinek et al., 2002). Research conducted by Yoshikawa et al using VEGF as an additional biological material after ACL reconstruction of sheep. There was a significantly greater angiogenesis formation in the tunnel graft in the treatment group than in the control group (Yoshikawa et al., 2006).

Research conducted by Ferdiasis et al on ACL reconstructed models treated by BM-SCs 
and VEGF intraarticular showed that there was no significant difference between treatment group and control group at week 3 evaluation. Significant differences between the control group and the treatment group occurred at the sixth-week evaluation. This indirectly indicates that there is an acceleration to the integration process between bone with tendon graft (Ferdiansis, 2014).

In this study, there was a significant difference in the thickness of collagen fiber or Sharpey's fiber significantly in both the femoral tunnel and the tibia tunnel in the third and sixth-week observations.. This result is consistent with the research conducted by Faridyan et al on the ACL reconstruction model which is treated intravenously by BMSCs and VEGF. The study showed significant

\section{REFERENCES}

Adachi, N. et al., 2004. Reconstruction of The Aanterior cruciate ligament. Singleversus double-bundle Multistranded Hamstring Tendons. The Journal of bone and joint surgery. British volume,86, pp.515-520.

Alpert, JM et al., 2008. patellar tendon anterior cruciate Ligame Autograft for Reconstruction. In B. Cole, J. Sekiya, \& LS Matthews, eds. Surgical Technique of the Shouder, Elbow, and Knee in Sports Medicine. Philadelphia: Saunders.

Anthony, AS \& Brian, B., 2006. Sports Medicine. Orthopedic Surgery Essential 1st ed., Philadelphia: Lippincott Williams \& Wilkins. differences in the mechanical ultimate tension strength increase between treatment groups compared with the control group in both the third-week observation and the observation of the sixth week (Faridyan, 2015). In this study, no markering was conducted on BM-SCs, so it can not be proven whether the accelerated growth is due to the given BM-SCs or hostderived cells.

\section{CONCLUSION}

There is an effect of injection of BMSCs and VEGF intratunnel after ACL reconstruction characterized by the histologic picture of increased thickness of collagen fiber or Sharpey's fiber network that is directly proportional to pullout strength

Ardern, CL et al., 2011. Return to sport following anterior cruciate ligament reconstruction surgery: a systematic review and meta-analysis of the state of play. British Journal of Sports Medicine, pp.1-11.

Arnoczky, SP et al., 1993. Anatomy of the anterior cruciate ligament. In Jackson DW, ed. The anterior cruciate cruciate ligament: Current and Future Concepts .New York: Raven Press, pp. 5-33.

Bartlett, RJ, Clatworthy, MG \& Nguyen, TN V, 2001. Graft SELECTION IN RECONSTRUCTION OF THE anterior cruciate ligament. The Journal of bone and joint surgery. British volume, 83 
(July), pp.625-634.

Baxter, FR et al., 2010. Augmentation of Bone Tunnel Healing in anterior cruciate ligament grafts: Application of Calcium Phosphates and Other Materials. Journal of Tissue Engineering.

Boyer, J. \&Meislin, RJ, 2010. Double-bundle versus single-bundle ACL Reconstruction. Bulletin of the NYU Hospital for Joint Diseases, 68 (2), pp. 119-126.

Deehan, DJ \&Cawston, TE, 2005. The Biology of Integration of the anterior cruciate ligament. The Journal of bone and joint surgery. Britishvolume,87, pp.889-895.

Dong, Y. et al., 2012. Enhancement of Tendon - Bone Healing for anterior cruciate ligament (ACL) Reconstruction Using Bone Marrow-Derived Mesenchymal Stem Cells Infected with BMP-2. International Journal of Molecular Sciences,13, pp.13605-13620.

Faridyan, BV, 2015. At the Biomechanics Test Tendon Graft Model-Bone TunnelPostReconstruction of anterior cruciate ligament with allogenic Giving Bone Marrow Mesenchymal Stem Cells (BMSCs) and Vascular Endothelial Growth Factor (VEGF) Intratunnel.Airlangga University

Ferdiansis, 2014. Effect of Intraarticular Mesenchimal Bone Marrow Stem Cells and Vascular Endothelial Growth Factor on Graft-Tunnel after ACL Reconstruction Integration .Airlangga University.

Fremerey, RW et al., 2000. Proprioception After Rehabilitation and Reconstruction in
Knees with deficiency of the anterior cruciate ligament: A Prospective, Longitudinal Study. The Journal of bone and joint surgery.British volume,82 (6), pp.801-6. Available at: http://www.ncbi.nlm.nih.gov/pubmed/109 90300.

Gardner, RL, 2002. Stem cells: Potency, Plasticity and Public Perception. Journal of Anatomy,200 (3), pp.277-282.

Griffin, LY et al., 2006. Understanding and Preventing noncontact anterior cruciate ligament Injuries: A Review of the Hunt Valley II Meeting, January 2005. The American Journal of Sports Medicine, 34 (9), pp.1512-1532.

Griffin, MD, Ritter, T. \& Mahon, BP, 2010. immunological aspects of allogeneic mesenchymal stem cell therapies. Human genetherapy,21 (12), pp.1641-55.

Hauser, RA et al., 2013. Ligament Injury and Healing: A Review of Current Clinical Diagnostics and Therapeutics. The Open Rehabilitation Journal,6, pp.1-20.

Hays, PL, 2008. The Role of macrophages in Early healing of a tendon graft in a bone tunnel. The Journal of Bone and Joint Surgery (American),90 (3), p.565.

Kaplan, LD \& Fu, FH, 2004. Clinical Applications of Tissue Orthopedics Engieering: Tendons and ligaments. In VM Goldberg \& AI Caplan, eds. Tissue Engineering Orthopedics Basic Science and Practice.New York:Taylor \& Francis.

Kweon, C., Lederman, ES \& Chhabra, A., 2013. Anatomy and Biomechanics of the cruciate ligaments and Their Implications 
Surgical. In Fanelli GC, ed. The Multiple

Injured Knee Ligament: A Practical Guide

to Management. New York: Springer-

Verlag, pp. 17-27.

Lim, J.-K. et al., 2004. Enhancement of Tendon Graft Osteointegration Using Mesenchymal Stem Cells in A Rabbit Model of anterior cruciate ligament Reconstruction. Arthroscopy: The Journal of Arthroscopic \& Related Surgery,20 (9), pp.899-910.

Liu, S. et al., 1997. Morphology and matrix composition during early tendon to bone healing. Clinical Orthopedic and Related Research, June (339), pp.253-60.

Lodish, H. et al., 2000. Collagen: the fibrous protein of the matrix. In Molecular Cell Biology.New York: WH Freeman Ed.

Ma, CB et al., 2007. Bone Morphogenetic Proteins-Signaling Plays A Role In Tendon-to-Bone Healing: A Study of rhBMP-2 and Noggin. The American journal of sports medicine, 35 (4), pp.597-604.

Martinek, V. et al., 2002. Enhancement of Tendon-Bone Integration of anterior cruciate ligament grafts With Bone Morphogenetic Protein-2 Gene Transfer: A histological and biomechanical Study. The Journal of bone andjoint surgery. American volume, 84, pp.1123-1131.

Milano, G., Deriu, L. \& Fabbriciani, C., 2007. Graft-Tunnel Healing. In C. Prodromos et al., Eds. The anterior cruciate ligament: Reconstruction and BasicS cience .Philadelphia: Elsevier Health

Sciences.

Myklebust, G. \& Bahr, R., 2005. Return To Play Guideines After Surgery The anterior cruciate ligament. British Journal of Sports Medicine, 39, pp.127132.

Ouyang, HW, 2004. Use of Bone Marrow Stromal Cells for Tendon Graft-to-Bone Healing: histological and immuno histochemical Studies in a Rabbit Model. American Journal of Sports Medicine, 32 (2), pp.321-327. Available at: http://ajs.sagepub.com/content/32/2/321.1 ong\#ref-8.

Ratajczak, MZ et al., 2007. A Hypothesis For An Embryonic Origin of Pluripotent Oct$4+$ Stem Cells In Adult Bone Marrow And Other Tissues. Leukemia, pp.860867.

Rodeo, SA et al., 1993-Tendon Healing in a Bone Tunnel. The Journal of Bone and joint surgery,75 (12).

Sipola, A., 2009. Effects of Vascular Endothelial Growth Factor (VEGF-A) And Endostatin On Bone, Oulu: Oulu University Press.

Smith, BA, Livesay, GA \& Woo, SL, 1993. Biology and Biomechanics of the anterior cruciate ligament. Clinics in Sports Medicine,12 (4), pp.637-70. Available at: http://www.ncbi.nlm.nih.gov/pubmed/82 61518.

Starman, JS et al., 2007. Anatomy and Biomechanics of the anterior cruciate ligament. In C. Prodromos et al., Eds. The anterior cruciate Prodromos 
Ligament: Reconstruction and Basic Science. Philadelphia: Elsevier Health Sciences, pp. 3-11.

Sun, L. et al., 2012. Inhibitory Effect of synovial Fluid On-To-Bone Tendon Healing: An Experimental Study in Rabbits. Arthroscopy: The Journal of arthroscopic and related surgery: official publication of the Arthroscopy. Association of North America and the International Arthroscopy Association, 28 (9), pp.1297-305.

Weiler, A. et al., 2002 Tendon Healing In A Bone Tunnel. Part II. Arthroscopy:The Journal of Arthroscopic \& amp; Related Surgery,18 (2), pp.124-135.

Williams III, RJ et al., 2004. The anterior cruciate ligament Reconstruction with a Four-Strand Hamstring Tendon
Autograft. The Journal of Bone and Joint

Surgery (American), 86-A, pp.225-232.

Woo, SL-Y. et al., 2006. Biomechanics of Knee ligaments: Injury, Healing, And Repair. Journal of Biomechanics,39 (1), pp.1-20.

Yoshikawa, T. et al., 2006. Effects of Local Administration of Vascular Endothelial Growth Factor on Mechanical Characteristics of the semitendinosus tendon graft anterior cruciate ligament After Reconstruction in Sheep. The American Journal of Sports Medicine, 34 (12), pp.1918-1925.

Zhang, F. et al., 2003. Effect of Vascular Endothelial Growth Factor On Rat Achilles Tendon Healing. Plastic and reconstructive surgery, 112, pp.16131619. 